\title{
PENGARUH TEMPERATUR DAN WAKTU TERHADAP KERAS ENDAP (PRECIPITATION HARDENING) PADA CONNECTING PAD SEPEDA MOTOR VESPA
}

\author{
Oleh : \\ Adid A. Hermansyah"), Hafid ${ }^{* *}$, dan George $\left.{ }^{* * *}\right)$
}

\section{INTISARI}

Connecting Pad adalah suku cadang sepeda motor vespa berbahan perunggu. Adapun letaknya berada diantara kopling dan penekan kopling yang berfungsi sebagai bantalan penghubung agar kopling berjalan dengan baik. Connecting pad lokal mempunyai umur yang lebih pendek dibanding dengan yang asli. Perbedaan umur pakai antara produk lokal dengan yang asli disebabkan oleh sifat kekerasannya, hal ini kekerasan akan melibatkan ketahanan terhadap aus. Pada umumnya pengerasan pada material perunggu dilakukan dengan pengerjaan dingin atau menambah unsur paduannya, namun pada material connecting pad ini dilakukan pengerasan dengan proses keras endap (precipitation hardening), dimana proses ini sangat dipengaruhi oleh temperatur dan waktu sehingga pada proses pelaksanannya temperatur harus sesuai untuk material yang akan diproses dan juga waktu penuaannya (aging) pun harus tepat agar terdapat hasil yang diinginkan.

Kata kunci-kata kunci : keras endap, connecting pad, penuaan.

\section{ABSTRACT}

Conecting Pad is made from bronze for vespa spare part. The connecting pad location is between clutch and clutch. This pad is for connecting bearing, therefore the clutch can work properly. Local connecting pad has lifetime shortly compared with original pad because its hardening property. This hardening property will influence wear resitance. Generally, bronze hardening is gained by cold treatment process or adding alloy element, but in this connecting pad precipitation hardening shall be used. This process is influenced by temperature and time. To get local connecting pad as good as original pad property, the time and temperature during process should be selected properly and aging process must be set accurately.

Keywords : precipitation hardening, connecting pad, aging.

\section{PENDAHULUAN}

Dasar utama dilakukan penelitian terhadap produk lokal Connecting Pad pada kendaraan bermotor Vespa adalah untuk meningkatkan umur pakai yang sesuai dengan produk aslinya (original). Material Connecting pad adalah terbuat dari bahan perunggu atau paduan antara tembaga $(\mathrm{Cu})$ dengan timah putih (Sn) yang fungsinya sebagai bantalan penghubung antara penekan kopling dan kopling agar dapat bekerja dengan baik. Ada dua macam material Connecting pad yang beredar di pasaran yaitu produk luar dan produk lokal.

Menurut informasi dari para pemakai bahwa material Connecting Pad produk lokal mempunyai umur pakai jauh lebih pendek dari produk luar (original), hal ini jelas sangat merugikan bagi para pemakai produk lokal tersebut.
Atas dasar permasalahan diatas maka dilakukan penelitian pada material Connecting Pad produk lokal dengan tujuan memperbaiki sifat mekaniknya khususnya kekerasan, dimana secara teoritis kekerasan sejalan dengan ketahanan aus. Dengan kata lain apabila suatu material semakin keras maka akan semakin tahan aus, dengan keras endap (precipitation hardening) pada material Connecting Pad. Diharapkan bahan perunggu ini akan menjadi keras, dikarenakan adanya atom-atom Sn tidak sempat berdifusi keluar dan tejebak didalam atom-atom $\mathrm{Cu}$ pada pendingin cepat, sejalan dengan waktu atom-atom Sn yang terjebak akan berdifusi keluar dan mengendap membentuk endapan yang halus dan menyebar yang menyebabkan kekerasan sekaligus kekuatan meningkat. 


\section{LANDASAN TEORI}

Material Connecting Pad terbuat dari bahan perunggu atau paduan tembaga $(\mathrm{Cu})$ dan timah putih $(\mathrm{Sn})$ yang secara teoritis unsur-unsur tersebut merupakan yang paling dominan dalam menentukan klasifikasi material tsb. Untuk lebih jelasnya kita uraikan sifat fisik dan mekanik dari kedua unsur adalah sebagai berikut :

1. Tembaga ( $\mathrm{Cu}$ : Cuprum) :

Tembaga berwarna merah, titik lebur $1.083^{\circ} \mathrm{C}$ mempunyai sel satuan FCC, bidang patahan berserat halus dan merupakan penghantar panas \& listrik yang baik. Tembaga murni mempunyai sifat lunak, ulet, dan hanya memiliki kekuatan rendah serta dapat dikeraskan melalui pembentukan dingin (cold working), dapat dilunakan kembali melalui proses perlakuan panas (heat tretment) antara $300{ }^{\circ} \mathrm{C}-700{ }^{\circ} \mathrm{C}$. Tembaga murni sangat buruk pada saat dicor (casting) karena akan terjadi poripori (porosity) pada saat pendinginan.

2. Timah putih (Sn : Stanum) :

Warnanya mirip perak dengan titik lebur $232{ }^{\circ} \mathrm{C}$, mempunyai sel satuan BCT, plastisitasnya cukup tinggi sehingga regangnya (elongation) dapat mencapai $30-50 \%$. Timah putih mempunyai fasa $\alpha$ (alpa) dan $\beta$ (beta), tetapi pada temperatur dibawah $13,2^{\circ} \mathrm{C}$ akan terjadi perubahan fasa yaitu fasa $\beta$ menjadi fasa $\alpha$ dalam bentuk puder yang disebut pes timah. Timah putih dalam udara dan air warnanya tidak akan berubah tapi mudah larut dalam asam dan basa keras. Timah putih termasuk kedalam logam lunak yang mudah dicor dan dipipihkan dengan baik yang dikenal sebagai staniol atau kertas timah. Mengingat sifatnya yang lunak dan harganya mahal, maka hampir tidak pernah dipakai dalam keadaan murninya, biasanya dipadukan dengan $\mathrm{Cu}, \mathrm{Pb}$, dan $\mathrm{Sb}$.

3. Paduan tembaga $(\mathrm{Cu})$ dan timah putih (Sn) :

Tembaga adalah logam non ferro yang dapat dipadu dengan beberapa unsur logam non ferro lain, seperti : $\mathrm{Al}, \mathrm{Zn}$, dan Sn. Unsur paduan ini memberikan sifat yang lebih baik dari tembaga murni untuk beberapa pemakaian.
Paduan tembaga $(\mathrm{Cu})$ dan timah putih (Sn) disebut juga perunggu dalam arti yang sempit, tetapi dalam arti yang luas perunggu berarti paduan tembaga $(\mathrm{Cu})$ dengan unsur logam selain dari unsur Sn. Perunggu $\alpha$ (alpa) mempunyai sel satuan FCC (Face Centre Cubic) dimana perunggu juga merupakan paduan yang mudah dicor dan mempunyai kekuatan yang lebih tinggi. Demikian juga ketahanan ausnya dan ketahanan korosinya cukup baik, sehingga banyak digunakan pada bidang teknik maupun untuk barang-barang kerajinan. Dengan demikian paduan $\mathrm{Cu}$ - $\mathrm{Sn}$ merupakan salah satu paduan yang menunjang peranan penting pada bidang pemesinan.

\section{METODE PENELITIAN}

Untuk mengetahui penelitian material Connecting Pad, maka dilakukan pemeriksaan dan pengujian sebagai berikut : pemeriksaan visual, pemeriksaan makroskopis dan mikroskopis, pengujian kekerasan, pengujian komposisi kimia, sebagai ilustrasi dapat dilihat pada gambar 1 . diagram alir tahapan penelitian.

\subsection{Data Material}

1. Material dasar :

Material Uji yang dipilih untuk Connecting Pad (gambar 2) adalah material produk lokal yang sering mengalami keausan, adapun keausan tersebut salah satunya disebabkan oleh kekerasan yang rendah yaitu $42,2 \mathrm{BHN}$, bila material produk lokal ini dibandingkan dengan material produk luar (original) yang lebih tahan keausannya dengan kekerasan mencapai 55,7 BHN dari hasil uji spektrometri pada material Connecting pad baik yang asli maupun yang lokal mempunyai komposisi kimia seperti tabel 1.

Tabel 1. Hasil uji komposisi kimia Connecting Pad

\begin{tabular}{|c|c|c|c|c|c|}
\hline \multirow{2}{*}{ Material } & \multicolumn{5}{|c|}{ Berat (\%) } \\
\cline { 2 - 6 } & $\mathrm{Cu}$ & $\mathrm{Sn}$ & $\mathrm{Zn}$ & $\mathrm{Ni}$ & $\mathrm{Si}$ \\
\hline Asli & 98.08 & 0.35 & 0.01 & 0.45 & 0.09 \\
\hline Lokal & 97.21 & 0.01 & 0.49 & 0.45 & 0.09 \\
\hline
\end{tabular}




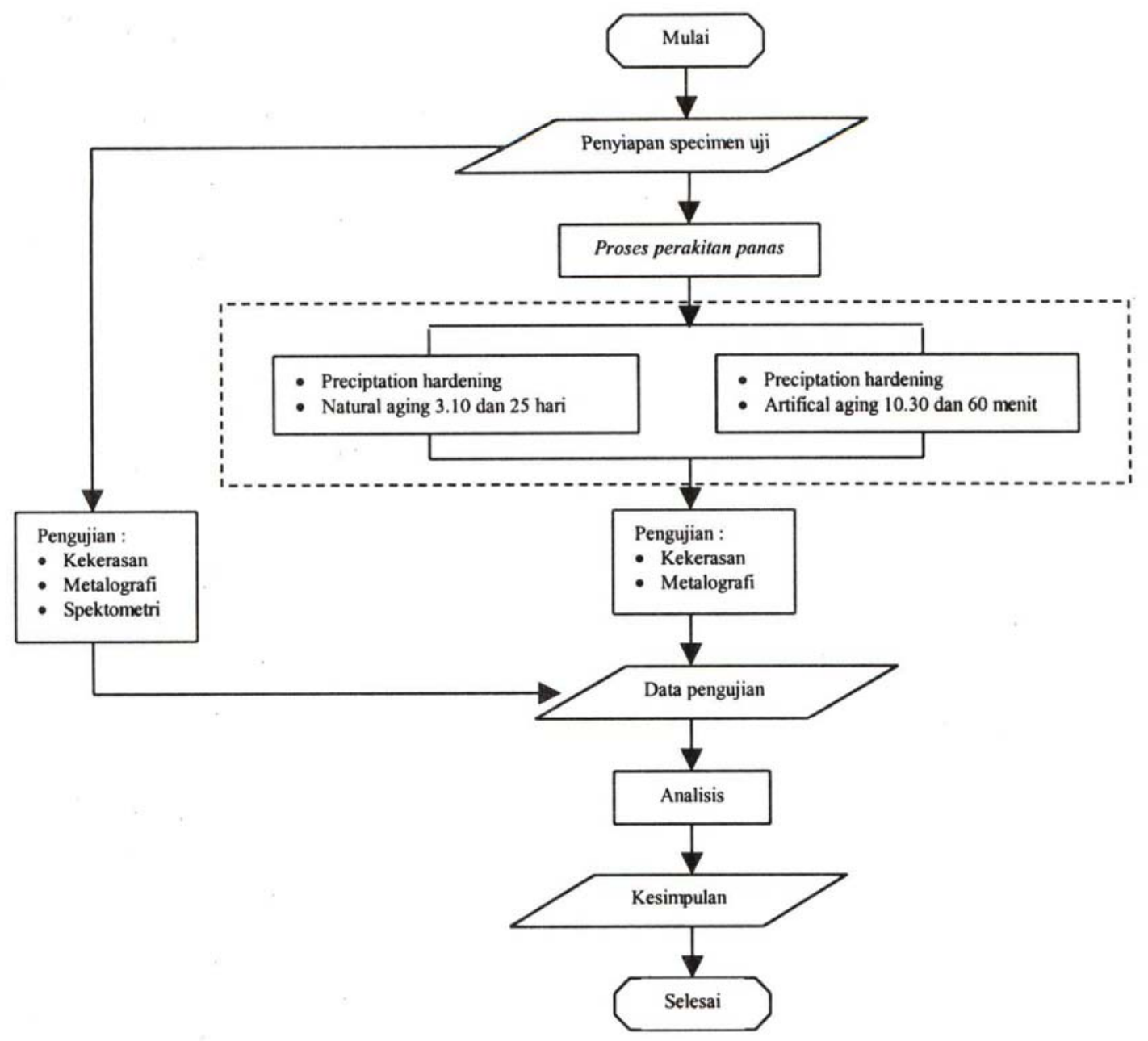

Gambar 1. Diagram alir penelitian.

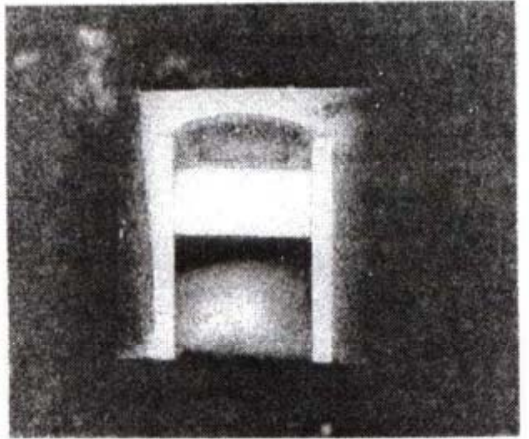

Gambar 2. Connecting Pad.

2. Proses perlakuan panas (heat treatment) : Proses perlakuan panas dimaksud untuk mengubah sifat-sifat mekanik logam dalam batas-batas tertentu.Adapun proses pemanasan dan pendinginan tergantung pada perubahan sifat logam yang dikehendaki serta tergantung pula pada jenis logam atau paduan yang diproses.
Perlakuan panas (heat treatment) secara umum adalah :

a. Pemanasan sampai suhu dan waktu tertentu (heating time).

b. Mempertahankan suhu sampai waktu tertentu (holding time).

c. Pendinginan dengan media pendingin,misalnya : air, air garam, oli, dan udara (quenching).

Adapun proses perlakuan panas (heat treatment), meliputi proses pengerasan dan pelunakan adalah sebagai berikut :

a. Proses pengerasan (hardening \& tempering).

b. Proses pelunakan (normalizing \& anealling).

3. Keras endap (precipitation hardening) pada perunggu :

Proses ini termasuk proses perlakuan panas (heat treatment), tetapi dalam hal ini memodifikasi temperatur dan waktu 
keras endap dari diagram kesetimbangan $\mathrm{Cu}-\mathrm{Sn}$ yang dilakukan didaerah $\alpha($ alpa $)$ untuk mendapatkan fasa Cu3-Sn, dimana fasa tersebut mempunyai keunggulan yaitu kekuatan yang tinggi, ketahanan yang aus dan tahan korosi air laut.

Perunggu dapat dikeraskan dengan presipitasi, dimana pada pelarutan pada larutan padat didaerah $\mathrm{Cu}$ mengikat menurut temperatur, kalau paduan ini didinginkan secara tiba-tiba dari larutan padat yang homogen pada temperatur tinggi dan kemudian dituakan (aging) pada temperatur yang cocok maka akan terjadi pengerasan oleh adanya fasa presipitasi yang halus dan terdispesi.

Dengan variabel pemanasan pada berbagai temperatur maka akan timbul fasa presipitat yang mempunyai ukuran berbeda, ukuran tersebut dimulai yang sangat kecil dan hanya terlihat dibawah mikroskrop elektron, sampai ukuran yang besar dan terlihat pada mikroskrop optik dengan pembesaran yang rendah. Adapun bentuk presipitaf bermacammacam seperti bola, plat, dan jarum.

Inti pada proses keras endap (precipitation hardening) pada perunggu dimana pada pemanasan atom-atom $\mathrm{Sn}$ akan terlarut pada $\mathrm{Cu}$. Pada pendinginan cepat atom-atom $\mathrm{Sn}$ tidak sempat berdifusi keluar akibatnya atom $\mathrm{Sn}$ terjebak dalam $\mathrm{Cu}$, larutan ini dinyatakan sebagai larutan padat lewat jenuh (super saturrated solid solution ).

Atom-atom Sn yang tadinya terjebak akan berdifusi keluar sejalan dengan lamanya waktu dan membentuk endapan (presipitat) yang halus dan mengebar. Fenomena tersebut adalah penuan pengerasan alami (natural age hardening).

Dengan terbentuknya endapan dapat pula dipercepat dengan memanaskannya pada temperatur lebih tinggi, yaitu diatas temperatur kamar (recoveri temperature) proses ini disebut pengerasan penuaan buatan (artificial aging).

4. Pengujian Kekerasan :

Pengujian kekerasan dilakukan pada kondisi awal sebelum material mengalami proses perlakuan panas, untuk mengetahui kekerasan awal dari material sebagai data awal, kemudian dilakukan proses pengerasan dengan precipitation hardening lalu quenching dalam air, setelah proses quenching terus dilanjutkan dengan penuaan alami (natural aging) dan penuaan buatan (artificial aging), dengan harapan mendapatkan hasil yang paling maksimal. Pengujian kekerasan ini dilakukan dengan metoda Brinell, adapun hasil pegujian dapat dilihat pada tabel 2 sebagai berikut :

Tabel 2. Hasil Uji Keras Brinell (BHN)

\begin{tabular}{|c|c|c|c|c|c|}
\hline \multirow[b]{2}{*}{ KOMODITI } & \multirow[b]{2}{*}{ KODE } & \multicolumn{4}{|c|}{ Uji Keras Brinell (BHN) Kgf/mm² } \\
\hline & & $\overline{1}$ & 2 & 3 & Rata-Rata \\
\hline Asli (Produk Luar) & A & 56.3 & 55.5 & 55.5 & 55.7 \\
\hline Local ( Produk Lokal) & $\mathrm{L}$ & 42.2 & 42.5 & 41.8 & 42.2 \\
\hline Produk Lokal setelah perlakuan panas & & & & & \\
\hline SHT $200^{\circ} \mathrm{C}$ Natural aging 3 hari & NA. $3 \mathrm{H}$ & 46.6 & 45.6 & 46.2 & 46.1 \\
\hline SHT $200^{\circ} \mathrm{C}$ Natural aging 10 hari & NA. $10 \mathrm{H}$ & 47.1 & 48.1 & 46.2 & 47.3 \\
\hline SHT $200^{\circ} \mathrm{C}$ Natural aging 25 hari & NA. $25 \mathrm{H}$ & 46.7 & 48.6 & 47.9 & 47.7 \\
\hline SHT $200^{\circ} \mathrm{C}$ Artificial aging $\left(120^{\circ}\right) 10$ menit & AA. $10 \mathrm{M}$ & 57.4 & 57.4 & 56.3 & 57.0 \\
\hline SHT $200^{\circ} \mathrm{C}$ Artificial aging $\left(120^{\circ}\right) 30$ menit & AA. $10 \mathrm{M}$ & 50.0 & 49.7 & 52.1 & 50.6 \\
\hline SHT $200^{\circ} \mathrm{C}$ Artificial aging $\left(120^{\circ}\right) 60$ menit & $\mathrm{AA} 60 \mathrm{M}$ & 50.7 & 50.2 & 50.2 & 50.3 \\
\hline
\end{tabular}


5. Pemeriksaan Mikrosruktur :

Pemeriksaan mikrostuktur bertujuan untuk mengetahui perubahan-perubahan stuktur akibat perlakuan panas dan didapatkan tampilan fasa stuktur mikro pada kondisi awal material sebelum dan sesudah proses presipitation hardening pada natural aging dan artificial aging. Sebagai ilustrasi dapat dilihat pada gambar 3-4-5-6-7-8-9-10.

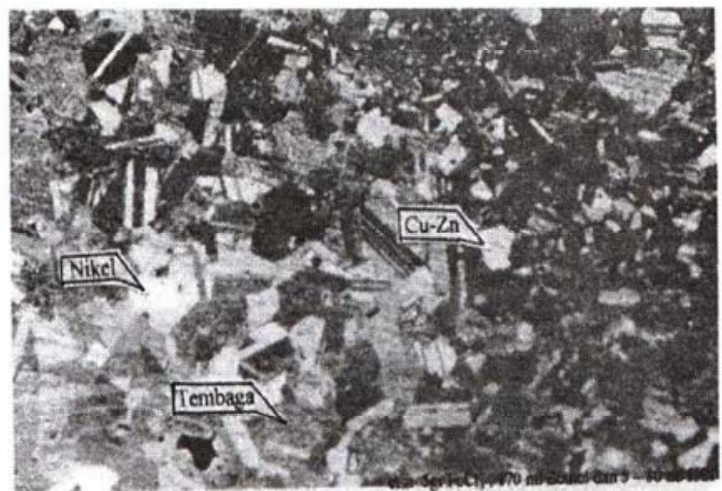

Gambar 3. Mikro struktur connecting pad asli $(300 \mathrm{X})$.

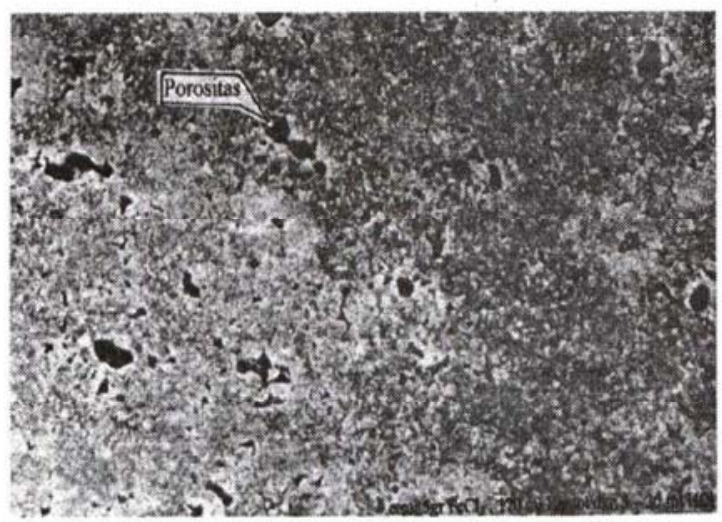

Gambar 4. Mikro struktur connecting pad lokal

Sebelum mengalami proses precipitation $(300 \mathrm{X})$.

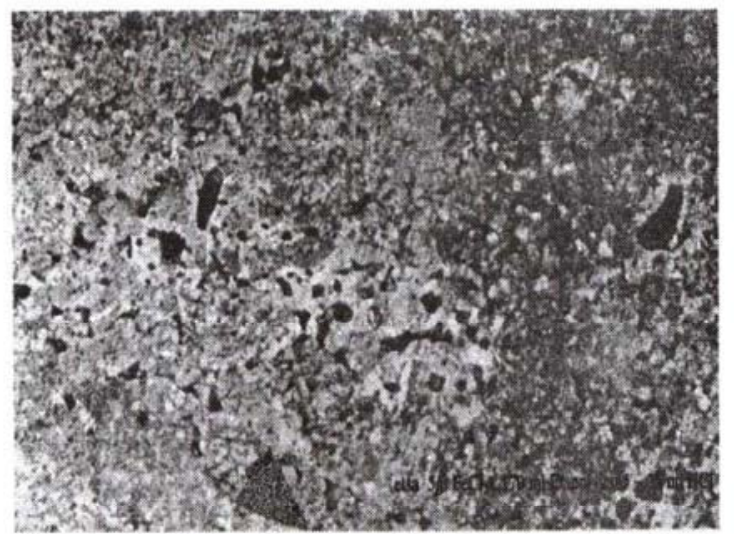

Gambar 5. Mikro struktur setelah proses precipitation hardening solution heat treatment (sht) $200^{\circ} \mathrm{C}$ natural aging 3 hari $(300 \mathrm{X})$
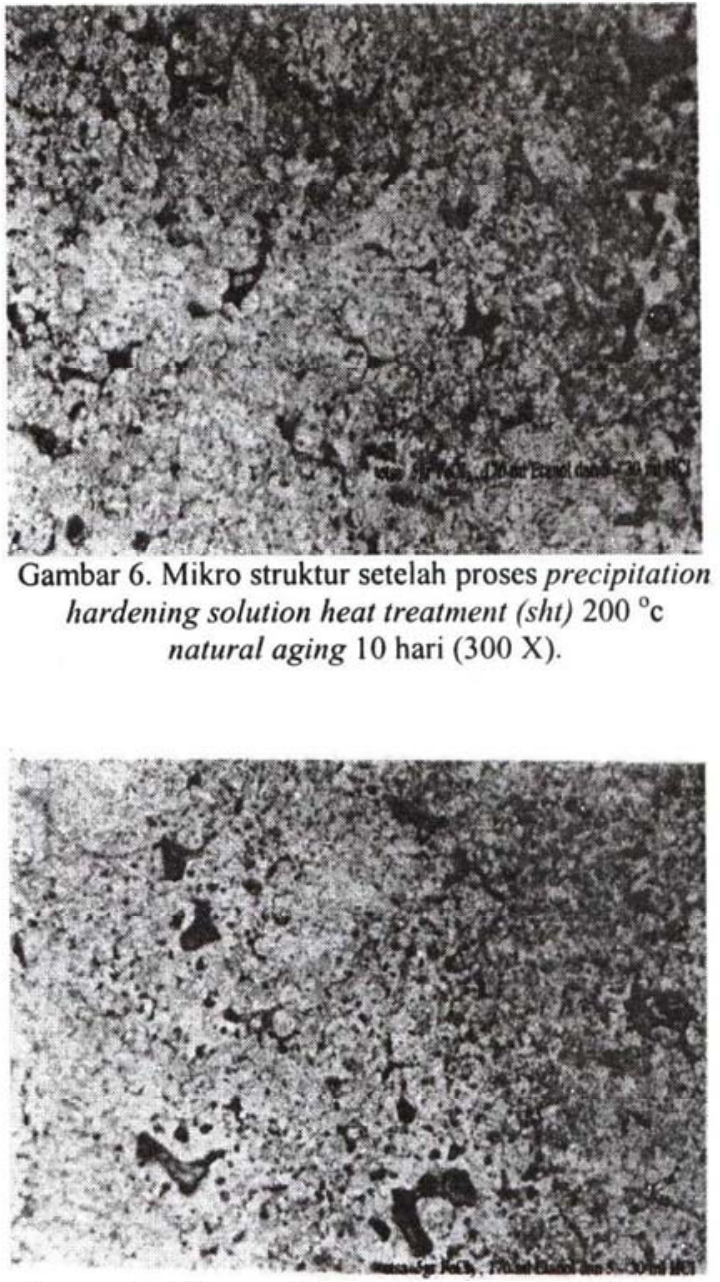

Gambar 7. Mikro struktur setelah proses precipitation hardening solution heat treatment (sht) $200^{\circ} \mathrm{c}$ natural aging 25 hari $(300 \mathrm{X})$.

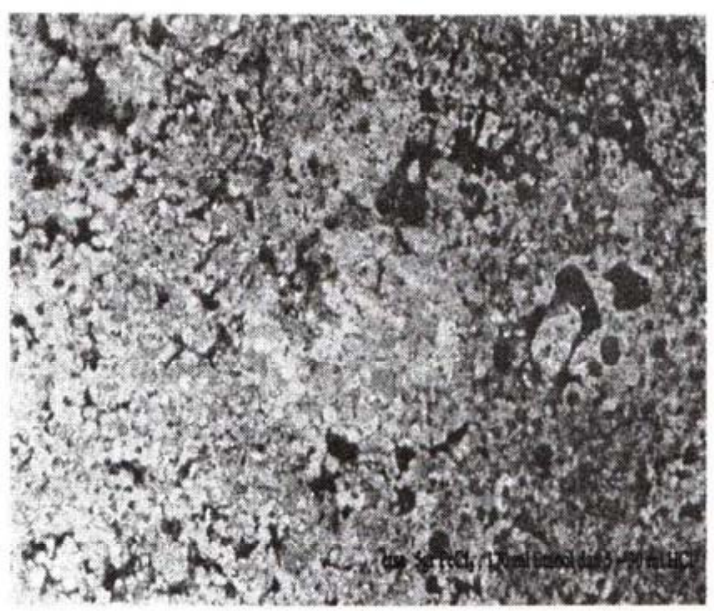

Gambar 8. Mikro struktur setelah proses precipitation hardening solution heat treatment (sht) $200{ }^{\circ} \mathrm{c}$ artificial aging $120^{\circ} \mathrm{c}, 10$ menit $(300 \mathrm{X})$. 


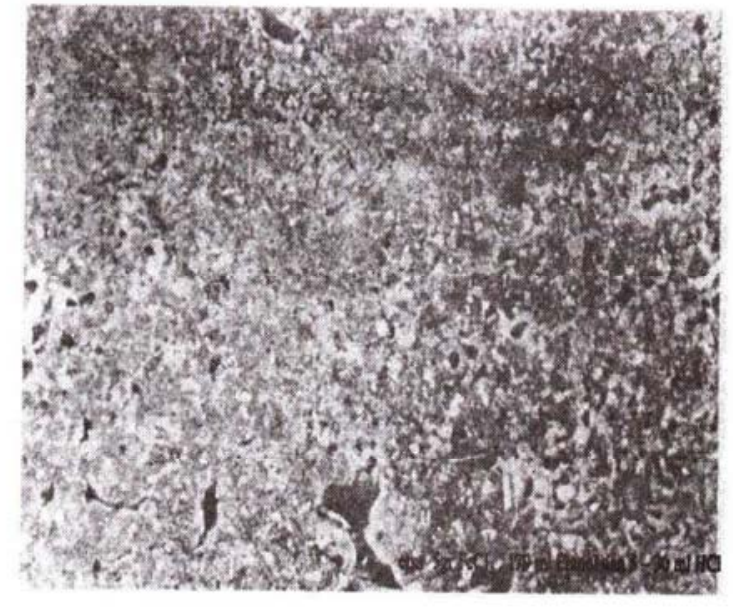

Gambar 9. Mikro struktur setelah proses precipitation hardening solution heat treatment (sht) $200{ }^{\circ} \mathrm{c}$ artificial aging $120^{\circ} \mathrm{c}, 30$ menit $(300 \mathrm{X})$.

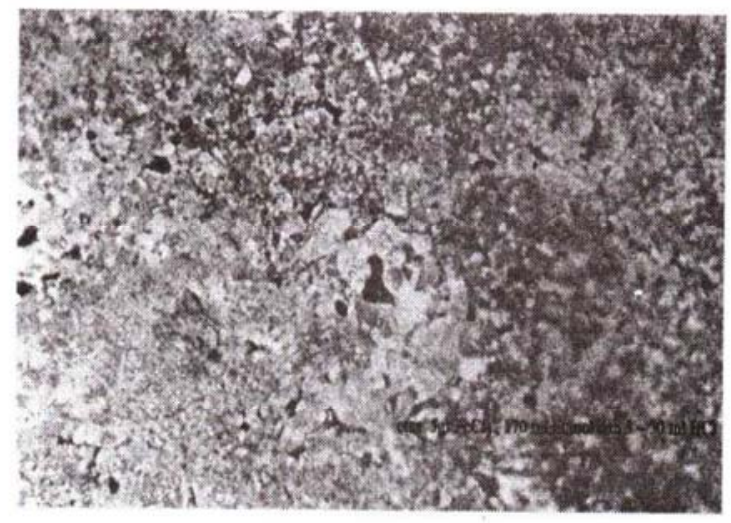

Gambar 10. Mikro struktur setelah proses precipitation hardening solution heat treatment (sht) $200{ }^{\circ} \mathrm{C}$ artificial aging $120^{\circ} \mathrm{c}, 60$ menit $(300 \mathrm{X})$.

6. Pemeriksaan Scanning Electron Microskop (SEM) :

Pemeriksaan dengan SEM tujuanya untuk lebih meyakinkan hasil dari mikroskop optik, mengingat hal ini merupakan suatu ciri yang khusus dari mikroskop adalah daya resolusi, yaitu jarak yang terkecil diantara dua titik dari suatu objek yang masih dapat diamati secara terpisah, makin besar daya resolusinya makin besar pula pembesaran yang dimiliki oleh alat tersebut. Maka perbedaan antara daya resolusi mikroskop optik lebih rendah dibanding dengan elektron mikroskop sebagai hasil dari Scanning Elektro Mikroskop (SEM) dapat dilihat pada gambar 11-12.

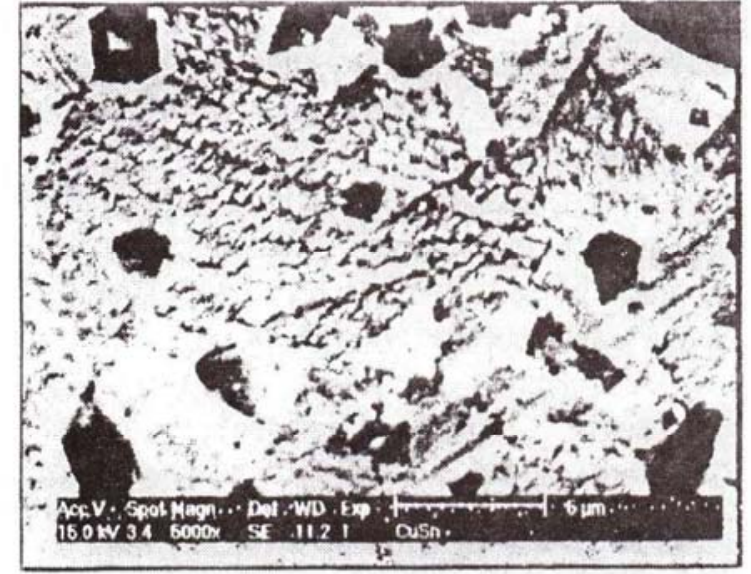

Gambar 11. SEM dengan pembesaran 5000X

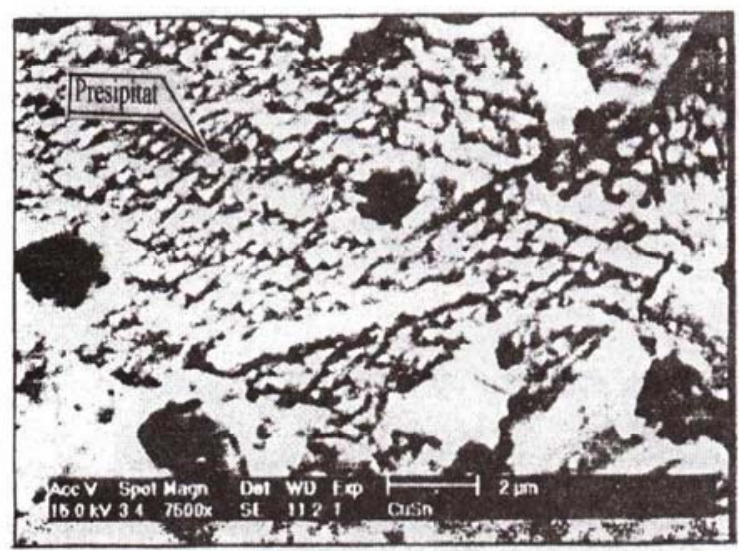

Gambar 12. SEM dengan pembesaran 7500X.

\section{HASIL DAN PEMBAHASAN \\ 4.1. Hasil Uji Keras}

Hasil pengujian kekerasan dari material Connecting Pad sebelum dan sesudah material mengalami proses Pesipitation Hardening dapat dilihat pada tabel 2, dimana kekerasan Connecting Pad lokal dari 42,2 BHN harus dapat mendekati kekerasan Connecting Pad asli dengan kekerasan 55,7 BHN.

Pada proses natural aging kekerasan dapat naik terus sejalan dengan waktu sehingga dapat mencapai angka kekerasan 47,7 BHN pada waktu penuaan 25 hari, kenaikan kekerasan ini diakibatkan Presipitat yang mulai tumbuh dan mengebar sesuai dengan lamanya waktu penuaan. 
Sedangkan proses Artificial Aging deangan waktu penuaan selama 10 menit, dengan suhu penuaan $120{ }^{\circ} \mathrm{C}$ kekerasan dapat melebihi kekerasan material Connecting Pad asli yang kekerasannya mencapai angka 57,0 BHN. Pada penuaan selama 10 menit dapat dikatakan paling maksimal dimana presipitat tumbuh dan menyebar, pertumbuhan presipitat pada artificial aging untuk waktu penuaan 30 dan 60 menit ternyata memberikan efek menurunya kekerasan sampai sekitar 50 $\mathrm{BHN}$, ini dimungkinkan karena pertumbuhan presipitat yang berlebihan atau dikenal dengan over aging.

\subsection{Analisis Struktur Mikro}

Sifat mekanik khususnya kekerasan pada perunggu Connecting pad ini ditentukan oleh tumbuhnya presipitat yang banyak halus dan menyebar, ada kemungkinan juga pengaruh unsure paduan dan proses pengerjaan yang lain.

Namun pada analisa ini hanya dilihat dari tumbuhnya presipitat yang berhubungan dengan waktu dan temperatur pada presepication hardening. Dalam analisis ini ukuran butir presipitat dan pengaruh perbedaan laju pendinginan diabaikan, dengan anggapan bahwa laju pendinginan yang dialami seluruh benda uji relatif sama, hal ini disebabkan karena ukuran benda uji yang relatif kecil.

Pertumbuhan presipitat pada perunggu terjadi setelah material mengalami larut pada lewat jenuh setelah di quench dalam air, proses tersebut telah masuk pada daerah Guiner Prestone (GP), dimana pada GP (1) awal dari peningkatan kekerasan, yang disebabkan karena atom Sn yang terjebak didalam larutan padat $\mathrm{Cu}$ mulai keluar atau tumbuh secara subtitusi sesuai dengan waktu penuaan (aging).

Dengan penambahan waktu penuaan pada daerah GP (2) atau $\varepsilon$ " dapat meningkatkan kekerasan, karena presipitat yang mulai tumbuh banyak dan menyebar akan terus tumbuh melewati fasa $\varepsilon$ '.

Dimana apabila waktu penuaan ditambahkan lagi maka $\varepsilon$-CuзSn akan berubah menjadi $\varepsilon$ - $\mathrm{Cu} 3 \mathrm{Sn}$, dimana presipitat yang tumbuh akan semakin besar dan kasar, sehingga presipitat yang tadinya mempunyai kesamaan letak (koheren) kehilangan sifat koherennya dengan semakin besarnya pertumbuhan presipitat yang menyebabkan turunannya nilai kekerasannya, disebut juga dengan penuaan yang berlebihan (over aging) mekanismenya dapat dilihat pada gambar 13 dibawah ini.

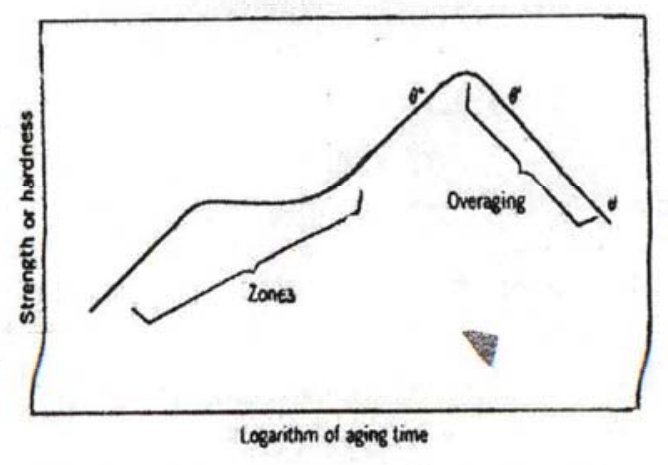

Gambar 13. Mekanisme terjadinya over aging .

Dimana mekanisme ini adalah mekanisme GP pada $\mathrm{Cu} \mathrm{Al}$ dan sesuai dengan mekanisme GP pada $\mathrm{Cu}-\mathrm{Sn}$ (perunggu)

\subsection{Analisis Temperatur Presipitation Hardening Terhadap Kekerasan \\ Karena perunggu Connecting pad ini} tidak ada kemiripan dengan seri-seri perunggu yan ada, maka untuk mencari temperatur solution heat threatment yang sesuai, mencoba mencarinya dengan cara mencoba tiap temperatur dari $150^{\circ} \mathrm{C}$ sampai $800^{\circ} \mathrm{C}$, sampai mendapatkan temperatur yang sesuai yaitu tempreatur dengan naiknya kekerasan.

Karena temperatur solution heat threatment merupakan proses awal yang memberikan pengaruh mendasar terhadap perubahan kekerasan dan awal dari proses penuaan. Pengaruh temperatur solution heat threatment dapat dilihat dari tabel dan gambar dibawah ini :

Tabel 3. Pengaruh temperatur solution heat threatment terhadap perubahan kekerasan

\begin{tabular}{|c|c|}
\hline Suhu $\left({ }^{\circ} \mathrm{C}\right)$ & Kekerasan rata-rata (BHN) \\
\hline 150 & 47 \\
\hline 200 & 50 \\
\hline 250 & 46 \\
\hline 300 & 45 \\
\hline 700 & 32,3 \\
\hline 800 & 32,3 \\
\hline 900 & 29,3 \\
\hline
\end{tabular}




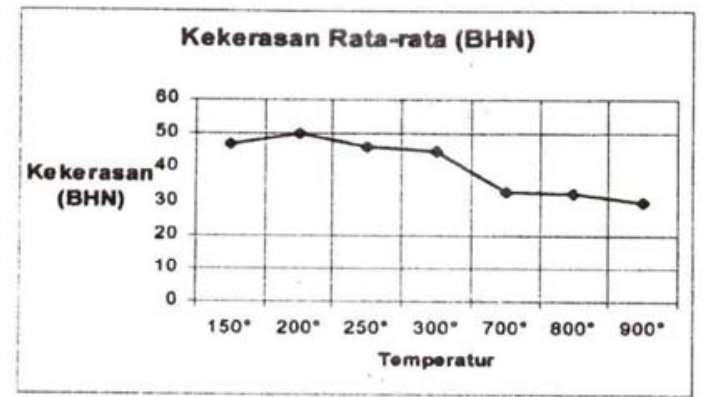

Gambar 14. Kurva pengaruh temperatur solution heat threatment terhadap kekerasan

Dari gambar 14 dan tabel 3 diatas terlihat temperatur solution heat threatment yang sesuai untuk material perunggu Connecting Pad, yang memberikan efek naiknya kekerasan yaitu pada temperatur $200^{\circ} \mathrm{C}$.Temperatur tersebut diperkirakan sesuai dengan teori yang ada.

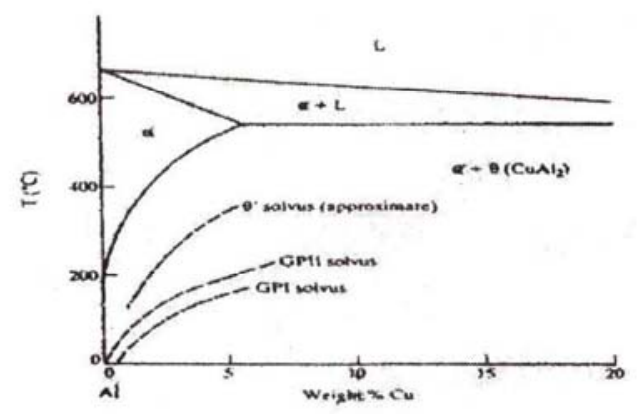

Gambar 15. Perkiraan daerah Guiner preston pada temperatur solution heat threatment.

Teori ini merupakan teori precipitation hardening pada $\mathrm{Cu}-\mathrm{Al}$ dimana daerah GP 2 atau $\varepsilon$ "' ialah daerah diantara suhu $200 \mathrm{C}$ dan kondisi ini sesuai bila diaplikasikan pada $\mathrm{Cu}-\mathrm{Sn}$ dengan kandungan Sn $1,7 \%$.

\subsection{Analisis Waktu Precipitation Hardening Pengaruh Waktu precipitation hardening pada proses natural aging \\ Dari tabel kita dapat melihat} pengaruh waktu terhadap kekerasan pada proses natural aging, dimana perubahan kekerasan yang terjadi tidak mencolok dalam artian selisih perbedaanya kecil, namun terlihat pada kurva kekerasanya semakin meningkat 3, 10 dan 25 hari, sesuai dengan lamanya waktu penuaan.

\subsection{Pengaruh Waktu precipitation hardening pada proses artificial aging}

Berbeda dengan natural aging, pada artificial aging peningkatan kekerasan yang terjadi cukup tinggi, ini disebabkan karena pada artificial aging dapat dicapai keadaan diamana pertumbuhan presipitat yang banyak dan menyebar.

Material yang kecil dengan tebal $3 \mathrm{~mm}$ tidak memerlukan waktu yang lama untuk artificial aging dengan waktu 10 menit sudah cukup untuk mendekati kekerasan connecting pad asli, bahkan melebihi sampai mencapai kekerasan $57 \mathrm{BHN}$, daerah dimana mencapai kekerasan yang meningkat tersebut adalah diantara GP (2) atau $\varepsilon$ ' dan $\varepsilon$ '.

Dan untuk lebih menyakinkan dengan munculnya presipitat -presipitat tersebut, maka hasil SEM yang dilakukan dengan proses EDAX untuk mengetahui kandungan yang ada apakah presipitat atau senyawa yang lain, dalam hal ini presipitat yang terjadi diperkirakan adalah fasa $\varepsilon$ (Cu3Sn).

Setelah dilakukan proses pemeriksaan pada daerah garis putih dari hasil pemeriksaan SEM dan EDAX adalah $\mathrm{Cu}-\mathrm{Sn}$ dan hasilnya dapat dilihat pada lampiran, maka presipitat yang terlihat adalah hasil precipitation hardening pada $\mathrm{Cu}-\mathrm{Sn}$ (perunggu ) dapat terjadi .

Sedangkan pada penuaan yang lebih lanjut pada 30 dan 60 menit berada pada daerah $\varepsilon$ ' menuju keseimbangan atau daerah $\varepsilon$ '( Cu3Sn ) yang di ikuti dengan penurunan kekerasan, proses ini disebut juga dengan penuaan yang berlebihan (over aging).

\section{KESIMPULAN DAN SARAN}

\subsection{Kesimpulan}

Dari data yang diperoleh dan analisis yang dilakukan dapat disimpulkan sebagai berikut :

1. Material Connecting pad asli merupakan brons (perunggu) tempa (wrought bronzes) berbeda dengan material connecting pad lokal yang merupakan perunggu cor (cast bronzes), perbedaanya dapat dilihat dari hasil metalografi.

2. Material Perunggu pada Connecting pad ini, tidak mempunyai kesamaan dengan seri-seri perunggu yang sudah ada pada 
ASM, sehingga tidak ada standarisasi dalam proses meningkatkan kekerasanya.

3. Kekerasan maksimum dengan angka 57 BHN dari proses precipitation hardening, diperoleh dari formula waktu dan temperatur operasi sebagai berikut :

- Proses solution heat threatment pada temperatur $200^{\circ} \mathrm{C}$, dengan waktu penahanan 20 menit, kemudian di quench pada air, kemudian dituakan pada temperatur $120^{\circ} \mathrm{C}$ dengan waktu penahanan 10 menit..

4. Faktor yang mempengaruhi sifat mekanik khususnya kekerasan pada perunggu ini adalah fasa $\alpha$ dan $\varepsilon$ (Cu3Sn) yang merupakan fasa utama dalam terbentuknya endapan atau presipitat yang memberikan sifat keras.

5. Waktu dan temperatur pada proses precipitation hardening merupakan hal yang penting sehingga dibutuhkan ketelitian dalam memulai pengerjaan.

\subsection{Saran}

Terdapat beberapa saran yang dapat diberikan untuk menyempurnakan dan mengembangkan analisis proses precipitation hardening pada tembaga $(\mathrm{Cu})$ dan paduannya ini adalah :

1 Material Connecting pad ini belum dicoba pada media pendingin lain seperti oli, sehingga kekerasan yang didapat sekarang kurang signifikan karena tidak adanya pembanding kekerasan dengan media lain.

2 Bila spesimen yang tersedia banyak atau besar, perlu dilakukan pengujian sifat mekanik yang lain baik uji impak maupun uji tarik.

3 Karena Connecting pad ini merupakan bagian yang bergerak dan bergesekkan maka akan lebih baik apabila dilakukan uji keausan untuk setiap proses precipitation hardening, guna mengetahui perbedaan laju keausan yang pada akhirnya dapat diketahui proses precipitation hardening yang mana laju keausannya paling kecil.

\section{UCAPAN TERIMA KASIH}

Penulis mengucapkan terima kasih kepada PT. Dirgantara Indonesia, Balai Besar Bahan dan Barang Teknik dan pabrik vespa yang telah membantu dan memungkinkan dilakukannya penelitian ini dari awal hingga selesai. Termasuk fasilitas peralatan laboratorium uji dan sumber pustaka berikut data sekunder yang sangat dibutuhkan untuk penyusunan makalah ini.

\section{DAFTAR PUSTAKA}

1. America Society of Metals, "Metals hand book Vol 7",Metals Park, ASM, 1978

2. Donald, S.Clark. Ph.D and Wilbur R Varneys , M.S."Physical Metallurgy for Engineers", Second Edition. D Van Nostrad Company., 1962

3. Henkel \& Pense,"Struktur Properties of Engineering Material" fifth edition Mcgraw Hill Book Co,Singapore.1993.

4. http://www.AmcorInternational.com.

5. Surahmat. "Hubungan Antara Kekerasan Dan Struktur Mikro Terhadap Ketahanan Aus Brons." Tugas Sarjana Jurusan Teknik Mesin. ITB, 1982.

6. Siswosuwarno Mardjono. "Material \& Metallurgy", Teknik Mesin ITB, Bandung, 1988.

7. Supardi. Rachmat. Drs, "Pengetahuan Metallurgy“. UNJANI, 1996.

8. Suratman, Rochim, "Panduan Proses Perlakuan Panas “. Lembaga Penelitian ITB, Bandung, 1994.

9. Surdia, Tata. Prof. Ir." Pengetahuan Bahan Teknik“, Pradnya Paramita, 1992.

10. Thomas.H.Courtney, "Mechanical Behavior Of Material", Mc GrawHill, International Edition.

11. William D, Callister, Ir. "Fundamental of Material Science and Engineering", 5 Edition.

12. William H, Cubberly, "Metal Hand Book Ninth Edition Volume 2",Metals Park, ASM.1979.

\footnotetext{
${ }^{7}$ Peneliti pada B4T, Bandung.

*) dan ${ }^{* * *}$ Peneliti pada MIDC Bandung.
} 